\title{
Vivências e práticas de cuidado de mulheres em processo de tratamento de câncer
}

\author{
Women's experiences and care practices \\ in the cancer treatment process
}

Pricilla Emmanuelly Oliveira ${ }^{1}$

Sílvia Maria Ferreira Guimarães ${ }^{1}$

\footnotetext{
${ }^{1}$ Faculdade da Ceilândia, Universidade de Brasília. QNN 04/Área Especial, Ceilândia Sul.

\begin{abstract}
This article seeks to understand the viewpoint of cancer patients about the disease process and the therapeutic procedures that they experience. Cancer treatments provoke a series of physical and emotional consequences in patients. Thus, patients undergo a restructuring of life and establish mechanisms to "take care of themselves." The methodology used was an ethnographic approach through interviews, field notes and participant observation. The ethnographic approach revealed how these women being given conventional treatment in a given hospital create shared care technologies based on sociability.
\end{abstract}

Key words Cancer, Technologies, Ethnography
Resumo Este artigo pretende compreender a visão das pacientes com câncer sobre o processo de adoecimento e os procedimentos terapêuticos que experimentam. Os tratamentos de câncer provocam uma série de consequências físicas e emocionais nas pacientes, assim, estas passam por uma reestruturação e elaboram mecanismos para "cuidarem de si". A metodologia utilizada foi a etnográfica, desencadeada por meio de entrevistas, anotações em diário de campo e observação participante. A etnografia revelou como essas mulheres, submetidas ao tratamento convencional em determinado hospital, criam tecnologias de cuidado compartilhadas baseadas na sociabilidade.

Palavras-chave Câncer, Tecnologias, Etnografia 


\section{Introdução}

O câncer de colo de útero é o segundo tumor mais frequente na população feminina, atrás apenas do câncer de mama, e a quarta causa de morte de mulheres por câncer no Brasil. Por ano, faz 4.800 vítimas fatais e apresenta 18.430 novos casos ${ }^{1}$. Diante desse quadro, Pinotti et al. ${ }^{2}$ afirmam que esse tipo de câncer é um dos principais problemas de saúde pública do mundo. Produz grande número de mortes na população de mulheres jovens e economicamente ativas, que desempenham importante papel social, seja no mercado de trabalho ou como centralizadoras das atribuições familiares. O principal fator de risco para o câncer de colo de útero é a infecção pelo Papiloma Vírus Humano (HPV). No entanto, de acordo com estudos médicos, os fatores socioeconômicos e ambientais, além de variados hábitos de vida, também são identificados como fatores de risco para o desenvolvimento da doença ${ }^{2}$. Portanto, essas pesquisas concluem que se trata de um problema de saúde pública que necessita de um aparato global para saná-lo, ou seja, social, econômico, político, físico e emocional ${ }^{3}$.

Este trabalho pretende discutir como essas mulheres vivenciam um processo de adoecimento marcado por estereótipos e preconceitos, imersas em redes de relações sociais que as condenam e aprisionam sob o estigma de doentes. Observase que a própria terapêutica envolvida estigmatiza essas mulheres e violenta suas corporalidades. Anjos $^{3}$ destaca que a medicina vem desenvolvendo tecnologias e procedimentos terapêuticos que levam à cura de diversas doenças e que têm aumentado a expectativa de vida das pessoas. No entanto, muitos dos métodos de diagnose e os tratamentos altamente sofisticados, ao mesmo tempo em que prolongam a vida dos pacientes, são agressivos, aumentando o sofrimento e ansiedade dos mesmos. Nessa lógica terapêutica, o foco principal ou os elementos de maior preocupação dos profissionais de saúde, em geral, recai sobre as próprias tecnologias, o corpo biológico do paciente, a doença em si, e a eficácia do procedimento ou a cura. Assim, a pessoa e sua vivência do processo ou experiência do adoecimento não são levadas em consideração. Isso demonstra um contraponto, pois ao lado de um desenvolvimento tecnológico sofisticado, acompanhado pelo escrutínio do corpo humano e a especialização no trato do mesmo, há uma limitação na construção da relação médico-paciente e na observação do paciente em sua totalidade e singularidade. A principal preocupação da medicina tem sido pôr fim à doença, utilizando de todos os meios possíveis a sua disposição e baseando-se, essencialmente, na tecnologia diagnóstica para coletar e medir os fatos clínicos ${ }^{4}$.

No caso específico do tratamento do câncer colorretal, Maruyama ${ }^{5}$ argumenta que os médicos dirigem seu foco exclusivamente para a doença, o tratamento, as complicações e probabilidades de retorno do tumor, negligenciando as situações sociais problemáticas e estigmatizantes vividas pelas pacientes, que, muitas vezes, são submetidas a cirurgias mutiladoras e efeitos colaterais avassaladores advindos dos tratamentos. Os problemas dessa negligência surgem no agravamento da ansiedade das pacientes e familiares, na impossibilidade de as pacientes executarem o autocuidado, o que significa perder o controle sobre o tratamento e, consequentemente, elevar o número de internações em decorrência dos efeitos colaterais, e no aumento da taxa de abandono do tratamento ${ }^{3}$. Diante desse contexto, cabe problematizar as terapêuticas que estão sendo impostas às mulheres de camadas populares, de grupos sociais historicamente excluídos de seus direitos de cidadania e do usufruto do direito à saúde na trama de um tratamento de câncer na rede pública. Este trabalho pretende realizar uma análise crítica sobre como mulheres que frequentam o Hospital Universitário de Brasília (HUB) estão vivenciando este processo.

\section{Metodologia}

Os procedimentos de investigação do problema em questão e as técnicas pertinentes a esses procedimentos tiveram como base os princípios do fazer etnográfico. As técnicas usadas no trabalho de campo foram baseadas em entrevistas e utilização de um diário de campo para anotações de vários fatos que ocorreram no ambiente de pesquisa, assim como as impressões pessoais da pesquisadora. Assim, a observação das pacientes no ambiente hospitalar foi complementada com entrevistas abertas com diferentes atores (pacientes e profissionais de saúde).

Segundo Cardoso de Oliveira ${ }^{6}$, o trabalho de campo com viés etnográfico contempla três momentos: o olhar, o ouvir e o escrever. O olhar e o ouvir cumprem a função de coleta de dados, enquanto o escrever faz parte do momento de análise e interpretaçao dos dados obtidos em campo. Assim, a pesquisa como um todo foi dividida nesses três momentos distintos, mas com vínculos estreitos. 
A fase de coleta de dados foi realizada entre os meses de fevereiro e maio de 2012, no Centro de Alta Complexidade em Oncologia (CACON) do Hospital Universitário de Brasília (HUB). Neste período, foram realizadas entrevistas abertas com mulheres portadoras de câncer de colo de útero, e com profissionais ligados ao tratamento. Antes da abordagem, a pesquisadora já havia ido ao CACON, algumas vezes, para conhecer o ambiente e a rotina das pacientes, para estabelecimento de uma relação de confiança e integração. À medida que as entrevistas eram realizadas, surgiram novos aspectos, o que levou à inclusão de outros temas.

As salas de espera do HUB foram os locais privilegiados do trabalho de campo, onde se deram os primeiros encontros com as pacientes. $\mathrm{O}$ HUB - em parceria com o Ministério da Saúde, o Instituto Nacional do Câncer e a Secretaria de Saúde do Distrito Federal - implantou o Centro de Alta Complexidade em Oncologia (CACON), em agosto de 2005. A parceria foi realizada com o objetivo de reestruturar os serviços de oncologia prestados no DF, bem como de atender à demanda crescente de casos de câncer no DF e no Brasil. O instituto de oncologia do HUB oferece serviços de radioterapia e quimioterapia, dispondo de um acelerador linear de fótons e elétrons, outro de braquiterapia de alta taxa de dose, um sistema de planejamento, e um dosimétrico, todos necessários para a instalação do serviço de radioterapia.

Foram entrevistadas pacientes que estavam em tratamento de braquiterapia no HUB, mas que já haviam passado por outros tipos de tratamento. Uma delas era casada e a outra divorciada; ambas com dois filhos; e com idade de 54 e 48 anos. Elas trabalhavam à época da descoberta do tumor, mas atualmente estão desempregadas. Por isso, são sustentadas pelo companheiro e/ou por suas famílias, contando inclusive com a ajuda de amigos. As duas mulheres se declararam católicas. Também foram entrevistados dois profissionais de saúde: um médico radioterapeuta e uma enfermeira. Não foram publicizadas imagens e nem gravações das pessoas entrevistas e, quando os entrevistados permitiram, foram feitas gravações das entrevistas a fim de melhor sistematizar os dados. Foram usados nomes fictícios para preservar a identidades dos sujeitos. No caso dos profissionais de saúde, foi usado o termo genérico "profissional de saúde" para preservá-los. As entrevistas para cada um dos sujeitos foram personalizadas, tendo em vista que a cada entrevista feita a mesma era transcrita e, a partir das respostas, um novo roteiro era elaborado, e uma nova entrevista era realizada. Isso ocorreu em um processo contínuo até ter um conjunto de informações que dava sentido às unidades de significados buscadas ${ }^{7}$. Essa personalização dos roteiros teve como intuito aprofundar as discussões com os entrevistados na tentativa de compreender suas representações sobre o tema tratado.

Para compreender as representações sobre o câncer e os procedimentos terapêuticos usados, tanto as entrevistas realizadas quanto as observações da pesquisadora estavam voltadas para determinadas unidades de significados, que foram as seguintes: noções sobre o corpo, saúde, doença e trabalho; os itinerários terapêuticos percorridos; e percepções sobre tecnologias. A partir do mapeamento dessas unidades de significados, o terceiro momento da pesquisa foi a análise dos dados gerados. O interessante desta fase é a forma explícita de interação entre os fatos observados e a teoria estudada. Enquanto, num dado momento, a teoria orientou a coleta dos dados, em outro, os fatos novos coletados causaram um incremento da teoria ou uma transformação da mesma ${ }^{6}$. Por fim, após esta terceira fase, só restou desenvolver o produto final, o trabalho escrito.

Cabe enfatizar que este trabalho é de cunho etnografico, portanto, não tem como proposta generalizar fatos, mas sim, a partir das experiências vividas por duas mulheres, captadas por meio de um trabalho minucioso e profundo, compreender a maneira como essas mulheres vivem cotidianamente, na rotina de suas vidas, uma terapêutica. As históricas contadas por essas mulheres permitem compreendermos experiências singulares de como, de fato, se efetivam práticas terapêuticas e a garantia do direito à saúde. Os procedimentos metodológicos desta pesquisa, com relação às implicações éticas na relação com os sujeitos da pesquisa, foram aprovados pelo Cômite de Ética em Pesquisa do Instituto de Ciências Humanas (CEP/IH) da Universidade de Brasília (UnB).

\section{Resultados e Discussão}

\section{Transformação da corporalidade das pacientes e a reestruturação de suas vidas}

Lidar com os estigmas e com a nova corporalidade força a pessoa a se reinserir de outra maneira nas suas relações sociais, na esfera do trabalho, do lazer, da vida sexual e reprodutiva. A descoberta da doença foi relatada pelas pacientes da seguinte maneira: 
Foi horrivel saber! Pensei: 'E agora? O que vou fazer?' Fiquei muito triste e chorava muito. Fiquei com muito medo e perturbada. Eu não tinha noção do que era a doença. Então para mim foi um choque, porque a única coisa que eu sabia é que muita gente está morrendo com câncer. Pensava o tempo todo que ia morrer. Passa pela cabeça da gente um questionamento de como foi a vida da gente. 'Por que eu não fiz isso ou aquilo?' Parece que o dia de morrer já está marcado e ia ser bem antes. Me falaram que o câncer tem cura. Não acreditei! E isso me deixava louca. Só fiquei mais tranquila quando conheci uma mulher que já estava curada. Ela foi meu consolo. (Dona Deuseli)

Outra paciente afirma:

Quando eu descobri que estava com a doença, estava passando por uma fase difícil: meu marido estava desempregado e resolvi não falar com ninguém. A doutora Vera [psicóloga do CACON] disse que eu neguei a doença nessa época. [...]. Por causa das dores e dos sangramentos, meu marido me obrigou a ir ao médico depois de um tempo. Acho que sem ele não ia estar aqui. Aí, hoje, eu falo para as mulheres que conheço fazerem exames, porque eu não queria no início e talvez podia ter começado a tratar antes. Eu pensei que não tinha jeito. A gente ouve dizer que quem tem câncer pode melhorar, mas depois a doença volta. (Dona Laís)

As falas dessas mulheres demonstram como a descoberta do câncer promove uma reestruturação em suas vidas, pois a morte está vinculada ao câncer e, agora, parece se concretizar diante das mesmas. Desse modo, é possível compreender o fato de muitas pessoas não mencionarem as palavras morte e câncer, que devem ser silenciadas. Isso acontece porque o termo câncer parece conter elementos mágicos que aproximam a morte, pois a palavra tem uma força de ação que pode desencadear o processo de morrer ou do câncer. Assim, usam-se metáforas para se referir à morte como "descansar", e, no caso do câncer, usa-se o silenciamento ou palavras substitutivas como "aquilo". Desse modo, percebe-se que o câncer, e tudo o que se relaciona com ele, inclusive seu nome, parece ser contagioso. Pronunciar a palavra câncer é uma forma de evocar a doença. Nas entrevistas, elas usavam o termo câncer, pois elas já se encontravam imersas no processo de adoecimento e estavam relatando sobre o mesmo.

Para essas pacientes, estar bem, ter saúde significa ter o corpo forte e pronto para o trabalho. Elas sentem a mudança, provocada, principalmente, pelo tratamento, no fato de não poderem mais ser ativas, trabalharem em casa ou na rua. Conforme afirma uma paciente, estar com saúde é:
Quando a gente pode trabalhar e não tem que ficar vindo em hospital direto. Agora eu venho toda semana, mas já está acabando. Aí, depois tem que esperar pra ver o que vai acontecer, fazer exame de novo pra ver se curou. [...] [O corpo] precisa estar bom para trabalhar, nós precisamos de saúde. (Dona Laís)

Outra mulher afirma que: "(saúde) é tudo na vida de alguém. Não sentir dor, nem tristeza, nem aquele desespero de não saber o que pode acontecer" (Dona Deuseli). A saúde está vinculada a um corpo que deve estar apto para o trabalho, pois essas mulheres vivem em determinados contextos em que a impossibilidade de levantar e estar pronta para o trabalho físico faz com que elas dependam de uma rede de solidariedade. Portanto, irmãs e outros parentes próximos auxiliam nos afazeres da casa. Assim, quando é perguntado a essas mulheres o que é doença, elas afirmam, a partir das experiências vividas com a neoplasia e das marcas deixadas pelo tratamento:

Eu estou doente agora. Não tem jeito de fazer muita coisa, trabalhar. A gente também não tem vontade de sair, nem na casa dessa minha irmã eu vou. É ela que vai lá em casa me ver e me ajudar com as coisas. Aí é difícil, porque a gente acostuma toda vida a fazer as coisas, sai de casa pra trabalhar, volta de noite e ainda arruma a casa da gente. Agora... (Dona Laís)

Sentir tudo de ruim, o corpo até pesa. Pode ser doença até da alma ou do coração, quando a gente fica tão triste que pensa que vai morrer de tanto chorar, de tanto sofrimento e medo (Dona Deuseli)

Sendo mulheres de uma classe popular que entendem precisar de seu corpo para o trabalho e dando muito importância a ele, elas relacionam o processo de adoecimento com a perda dessa qualidade corporal, do trabalho. Isso marca seu corpo e as relações sociais que elas mantêm com o mundo. Nesse sentido, ao longo do tratamento, que as deixa padecendo de um novo processo de adoecimento, uma das principais mudanças acontece com relação ao trabalho:

Eu trabalhava pra ajudar lá em casa. E teve uma época que meu marido ficou desempregado. Aí depois eu parei de trabalhar. Fiquei um tempo ainda trabalhando de diarista, mas depois também não deu mais e estou até hoje só arrumando as coisas lá de casa. Mas eu que faço tudo. A minha irmã me ajuda também, mas eu que lavo, passo e cozinho ainda [...]. Antes eu trabalhava em casa de família. Depois que descobri, aí parei. [...] Já tô melhorando e quero voltar a trabalhar logo. (Dona Laís)

Portanto, para essas mulheres, o corpo é instrumentalizado para a produção, para a manuten- 
ção da subsistência; afinal, elas são integrantes da classe trabalhadora urbana, cuja forma de sobrevivência repousa no uso da força física. Por esse motivo, a saúde é tão valorizada por essas mulheres, chegando a considerá-la como um bem.

Outro ponto a ser enfatizado é que no discurso dessas mulheres sobre o que é o câncer, elas o definem e analisam o contágio, tanto a partir do discurso médico, que as influencia, quanto do discurso popular. Conforme elas mesmas afirmam: "Eu pensei que não tinha jeito. A gente ouve dizer que quem tem câncer pode melhorar, mas depois a doença volta”. Outra mulher explica que: "Eu não tinha noção do que era a doença. (...) Me falaram que o câncer tem cura”. Por outro lado, sua condição de serem de uma classe popular faz com que elas sejam analisadas pelos profissionais de saúde por um viés preconceituoso e estigmatizante. De acordo com uma dessas mulheres, elas afirmam que: "os médicos falam que o câncer de útero é por causa de relação sexual desprotegida." Os profissionais de saúde entrevistados afirmam que o câncer é:

Uma doença de evolução lenta, muitas vezes de diagnóstico tardio. [...] O câncer é um problema social, envolve saúde, educação, assistência social [...]. A grande maioria das mulheres têm o vírus HPV. [...] E está relacionada com a iniciação sexual precoce, os muitos parceiros, ou seja, à promiscuidade. (Profissional de Saúde)

É um grupo de doenças que têm impacto social maior do que o lado clínico ou médico. [...] Os pacientes estão adoecendo por alcoolismo, cigarro, mulheres que não têm acesso ao Papanicolau todo ano [...]. 95\% dos casos são causados pelo HPV, mas a infecção pelo vírus precisa de 10 a 15 anos para se desenvolver, por isso, mais uma vez, se trata de um problema social. Essas mulheres não têm acesso ao exame preventivo [...]. Os outros $5 \%$ dos casos são causados por sindromes familiares, históricos genéticos da família, ou tumores histológicos de outros tipos [...]. Elas [pacientes] têm dúvidas sobre o próprio prognóstico, que é a doença. (Profissional de Saúde)

Então, percebe-se que, para os profissionais de saúde, a conduta dessas mulheres está relacionada com o desenvolvimento do câncer, por conseguinte, há um ideal de moralidade perpassando os discursos. Nesse sentido, o elemento social aparece nos discursos dos profissionais para justificar a existência de uma conduta moral, hábitos nocivos, que causam o câncer, e não para compreender outras racionalidades e relações sociais. Assim, esses profissionais entram em contradição ao afirmar que a infecção pelo vírus aconteceu há 10 ou 15 anos, mas que a conduta promíscua, contínua, é que faz o câncer aparecer. Contradições de um discurso que moraliza os sujeitos. Nesses discursos, também, estão inseridos o caráter punitivo por se ter o câncer, pois a pessoa desenvolveu a doença por algo errado que a pessoa tenha feito, isto é, a sua vida sexual, maus hábitos, etc.

As tecnologias usadas no tratamento requerem como autocuidado regras de condutas e higiene pautadas pelo viés biomédico, que desconhece a realidade dessas mulheres de classe popular e suas concepções sobre o corpo, sua vida social, seu processo de adoecimento. As consequências do tratamento são marcantes na corporalidade e na constituição dessas mulheres enquanto sujeitos. Isso se complexifica diante das afirmações dos profissionais de saúde entrevistados de que essas mulheres desenvolveram o câncer devido a sua vida promíscua e, agora, eles exigem no tratamento, que elas sigam as várias condutas enfatizadas, como, por exemplo, evitar aglomerações e contato com pessoas doentes, manter boa higiene oral e corporal, evitar quedas e ferimentos, utilizar escova dental de cerdas macias, manter alimentação adequada e higienizar os alimentos antes de seu consumo. Não se pretende afirmar aqui que essas mulheres não devam seguir esses procedimentos, mas o que se pretende mostrar é a mudança de conduta que elas devem passar, forçadas por uma tecnologia que não as vê em sua totalidade. Além disso, as definições de aglomerações, uma boa higiene e alimentação passam por interpretações moralizantes, por parte dos profissionais, que, muitas vezes, denigrem o universo de pessoas de classes populares e criam estigmas.

Há outros conflitos discursivos entre os profissionais de saúde e essas mulheres sobre modelos sexuais e reprodutivos, conforme veremos a seguir. No olhar dos profissionais, eles (os profissionais) vivem um modelo de vida sexual e reprodutiva que está no lado da cultura e o das mulheres de classes populares está no lado da natureza, do animal e irracional. Assim, elas são promíscuas e agem como animais em sua vida sexual e reprodutiva. Por outro lado, esses profissionais se veem como racionais, pois eles, no nível do discurso, afirmam ter somente um parceiro, "planejam seus filhos". De acordo com Ribeiro Corossacz ${ }^{8}$, há uma relação de classe entre médicos e pacientes, no Brasil, que toma forma nos corpos numa modalidade histórica específica: o corpo dos dominantes, descendentes de europeus, e dos dominados, descendentes 
de africanos e indígenas. Essa relação de classe apresenta, no discurso médico, a classe popular como irracional e a sua como civilizada, o que gera práticas preconceitosas e de violência institucional no momento do atendimento. Assim, os profissionais de saúde do HUB afirmam que essas mulheres parecem não formular uma reflexão sobre o que têm, por isso não há possibilidade de elas participarem ativamente do tratamento, negociarem sobre o mesmo:

[...] Elas [pacientes] são poucos instruídas. $O$ nivel e grau de escolaridade delas não permite essa participação [no tratamento] [...]. O paciente do serviço particular interroga mais, porque é mais informado. Antes de ir à consulta, ele pesquisa na internet, então, já chega sabendo o que é o tratamento [...]. As pacientes daqui têm um conhecimento limitado, um entendimento limitado. Às vezes eu explico, explico, explico e tenho certeza de que ela saiu daqui sem entender nada... por mais que a gente use uma linguagem mais simples. (Profissional de Saúde)

Muitas delas [pacientes] têm a grande preocupação se vai viver. Porque, às vezes, elas nem sabem o que têm. Os médicos não falam se o que elas estão fazendo é curativo ou simplesmente paliativo, um jeitinho que estão dando na doença. (Profissional de Saúde)

Portanto, na visão de alguns profissionais, essas mulheres estão imersas em uma ignorância que não cabe o diálogo, muito menos a participação no tratamento. Esses profissionais contradizem estudos que comprovam que as pacientes com câncer, que tiveram oportunidade de participar na tomada de decisão de seu tratamento, experimentaram menos ansiedade e depressão ${ }^{2}$. A forma como o tratamento ocorre verticalizado, sem abertura para uma negociação, é imposto a todas da mesma maneira, observando unicamente o corpo biológico e a especificidade exclusivamente do tipo de câncer e não a singularidade da pessoal enquanto sujeito político inserido em um contexto social, capaz de negociação e escolhas. No HUB, de acordo com relato de um profissional de saúde: "O tratamento é padronizado, primeiro faz a químio e a rádio juntas, e, depois, a braqui. Todas passam por isso. E é indicação médica".

Nos meandros da efetivação desse direito à saúde, a abordagem e explicação à paciente não são individualizadas, no sentido de respeitar sua capacidade de assimilação das informações, na qual as dúvidas acerca da doença podem ser esclarecidas. Após a confirmação do diagnóstico de tumor maligno, as mulheres começam a bus- ca por explicações para o aparecimento de uma doença considerada tão grave. Verifica-se que a percepção da doença, formada com base em uma pluralidade de aspectos e significados compartilhados socialmente, inclui também a experiência individual de cada uma das entrevistadas. $\mathrm{Na}$ medida em que se apropriam dos significados sociais da doença, seja do ponto de vista popular ou do ponto de vista médico, elas os confrontam com o seu comportamento ou com seus hábitos de vida, numa tentativa de reconhecer as possíveis causas para o aparecimento do câncer. E assim elas promovem uma releitura de suas vidas, das relações sociais mantidas, das emoções sentidas, das provações vividas e também do não vivido para explicarem porque estão com câncer:

Acho que é por causa da canseira que a gente vive né. Todo dia correndo muito e trabalhando dia e noite. Fiquei com medo e perturbada [quando descobri] (Dona Laís)

[...] Acho que foi porque Deus quis me colocar essa provação na minha vida. Pra me fazer persistir na fé e no Senhor. [...] A única coisa que eu sabia é que muita gente está morrendo de câncer. Pensava o tempo todo que ia morrer. Passa pela cabeça da gente um questionamento de como foi a vida da gente: 'Por que eu não fiz isso ou aquilo?'. Parece que o dia de morrer já está marcado e ia ser bem antes. [...] Porque eu tenho que ver minha neta crescer e ajudar a olhar ela ainda. E os meus filhos ainda precisam de mim. [...] Tenho que ficar com eles mais um tempo [...]. (Dona Deuseli)

Em suma, a concepção de corpo que organiza e ordena a prática social das mulheres entrevistadas está diretamente relacionada ao trabalho, à produtividade e à rede de relações sociais que irão mantê-las quando estiverem em tratamento, doentes e impossibilitadas de trabalharem. Tal concepção é elaborada a partir dos significados compartilhados pelo grupo social ao qual pertencem. À medida que é compreendida a forma como essas mulheres percebem o próprio corpo, entende-se o medo que têm de adoecer. A doença significa perda da capacidade de sustentação própria e do grupo familiar. Após passarem pelo tratamento, essas mulheres alteraram sua concepção sobre o processo de adoecimento e a relação que mantêm com seus corpos. Dona Deuseli afirma: "antes eu achava que não ficava doente, que era forte demais, que nunca ia dar essas coisas (...). Agora eu sei que todo mundo pode ter uma doença dessas." Já Dona Laís relata: "hoje, eu falo para as mulheres que conheço fazerem exames, porque eu não queria no início e talvez podia ter começado a tratar antes." 


\section{O itinerário terapêutico por procedimentos terapêuticos diversos}

Essas mulheres vivem um processo de adoecimento, portanto, elas não são doentes ou elas não se encontram em um quadro clínico estático9. Nesse sentido, elas transitam, conforme elas mesmas informaram, por procedimentos terapêuticos diversos, da automedicação à missa na igreja, da oração na televisão à braquiterapia. Desse modo, essas mulheres associam os tratamentos no HUB com outras terapêuticas, como, por exemplo, sistemas religiosos. Esse trânsito configura a idéia de itinerário terapêutico semelhante ao que foi discutido por Gerhardt ${ }^{10}$, que afirma ser este constitutivo de práticas e estratégias da população de baixa renda no enfrentamento de seus problemas cotidianos, sobretudo em relação à procura de cuidados em saúde $\mathrm{A}$ religiosidade permeia o discurso das pacientes sobre o aparecimento e o tratamento do câncer.

Nas falas das mulheres entrevistadas, verifica-se que elas se utilizam da fé e da religiosidade não só como uma forma de conforto e apoio, mas também como um instrumento que interpreta, organiza e explica os acontecimentos em que elas estão envolvidas, como o aparecimento do câncer e sua cura. Dona Deuseli afirma que:

Eu peço pra Ele interceder por mim, pra eu ficar curada de uma vez disso. Pra Ele me dar força porque eu tenho que ver minha neta crescer e ajudar a olhar ela ainda. E os meus filhos ainda precisam de mim. Esse meu menino que mora aqui até que não porque já casou, mas o outro precisa. Mas essa mulher que mora com ele também, ela não sabe muita coisa assim, não. Aí eu tenho que ficar com eles mais um tempo, mas também a gente tem que pedir pra Deus levar a gente na hora da vontade Dele.

$\mathrm{E}$ as orações são tanto de católicos quanto de evangélicos:

Eu acredito na Santa Maria porque ela é que intercede junto de Deus, de Jesus que é o filho dela. Se você pedir pra ela e ela pedir pra Jesus pode ter certeza que realiza, que te salvarão. Aí eu sempre peço pela interseção divina dela. Mas eu também leio orações de outros santos: Santo Expedito, São José, Santo Agostinho. Aqui em casa tem um monte daqueles papeizinhos que a gente pega na porta da igreja ou na rua, que o povo distribui. Eu leio até aqueles de crente, sabe! Mas eu sou católica, só que se eu recebo de alguém eu não posso jogar fora sem ler porque às vezes é promessa das pessoas, aí eu quebro a corrente dela [...]. Eu queria ter ido em Trindade [GO] porque lá tem muito benzedeiro bom mesmo, mas o meu filho não deu jeito de me levar. (Dona Deuseli)

As missas do Padre Moacyr [padre de Taguatinga] me ajudaram. Eu ia lá e me libertava de tudo que tava sentindo, todos os pensamentos ruins e todas aquelas dores, angústias. Fui um tempão lá porque era bom demais, não dava nem vontade de ir embora. Acaba tarde, você sabe que as missas lá vão até tarde da noite. Eu saía de lá com a minha irmã e a gente voltava de ônibus sozinha. (Dona Deuseli)

Sobre o tratamento no HUB, essas mulheres afirmam que passaram por vários. Dona Deuseli diz que iniciou o tratamento em 2011 e continuou até o início de 2012. No seu tratamento não fez cirurgia, porque "o médico falou que do jeito que está o câncer, não ia mexer em nada." Sobre os outros tratamentos, ela afirma que:

Fiz cinco ciclos [de quimioterapia], porque pode mudar a medicação durante o tratamento. Há remédios que a gente passa mais mal, há outros que a gente fica melhor [...], aí depende de cada um. Comecei no início de 2011, no mês de março e fiquei até outubro, novembro. [...] da braqui, eu lembro direitinho, tem menos tempo e é horrível. Foram quatro vezes, uma em cada semana. Comecei na última semana de janeiro, porque era até aniversário do meu filho no dia.

Outra paciente analisa o tratamento da braqui:

Sinto enjoo no estômago e calafrios até uns dois dias, depois de sair daqui. Dói também lá dentro, na hora que está fazendo. Assim, não dói, dói... é ruim! Incomoda [...]. Agora não volto mais! Acabei as quatro seções e tem que esperar. Me disseram pra voltar no médico, fazer outros exames e daí vai depender dos resultados. É difícil, né! Mas eu tenho sorte de ter gente que vem comigo toda semana. [...] Eu ainda não sei se curou! Mas eu acho que sim. (Dona Laís)

Quando são questionadas sobre se gostaram do tratamento no HUB e se ele foi efetivo, elas enfatizam os momentos quando se encontram nas salas de espera, a "salinha" e de conversa com as enfermeiras:

[...] Venho aqui e as enfermeiras conversam, elas têm muita paciência com o povo [...]. As enfermeiras eu via todo dia. Elas falavam do que tinha que fazer e perguntavam o que eu tava sentindo. 
Elas também ajudavam com os enjoos: 'isso é bom, mais isso não pode porque piora' [...] Elas [enfermeiras] explicam dos efeitos que podem acontecer por causa do tratamento e o que a gente tem que fazer quando acontecer. (Dona Deuseli)

Encontrei pessoas que me atendem com muita atenção e carinho. Todo mundo me chama pelo nome e todo dia que eu venho falo com as meninas [pacientes] ali da salinha. Eu acho muito bom! (Dona Laís)

Sobre as salas de espera da braqui e químio, a "salinha", cabe uma reflexão, pois no discurso dessas mulheres elas parecem criar uma terapêutica coletiva que subverte o que se entende como sala de espera dos hospitais. Além disso, nas entrevistas com essas mulheres, os momentos vividos na "salinha" foram os mais lembrados no processo de alívio do tratamento:

$\mathrm{Na}$ quimio, a sala [do tratamento] fica lá em cima. A gente chega cedo e espera a enfermeira chamar pra tomar a medicação, às vezes é rápido, mas, quando trocava a medicação, demorava mais. Lá tem lanche pra cada pessoa de um jeito, porque tem uns que podem comer isso, outros aquilo. Tem que ir acompanhada, mas a pessoa tem que ficar de fora naquela sala de TV esperando. Só se tiver alguma coisa que eles chamam. Tem uns dias da semana que vai gente voluntária tocar música também. A braqui faz embaixo mesmo. Também tem que chegar cedo porque passa pela consulta de enfermagem toda vez. A enfermeira falou que quando demora é porque a energia do equipamento está no fim, mas quando é nova é super rápido. Quando eu fui, demorou um pouco. As enfermeiras colocam as agulhas na gente e deixam lá até acabar. Também tem que ir com alguém pro caso de precisar. [...] Lá, quando a gente tava esperando, conversava com outras pessoas. No primeiro dia, eu já falei com uma senhora lá que tinha problema na mama. E na sala de químio, é sempre as mesmas pessoas, ai a gente acostuma e faz amizade. [...] Na sala de espera mesmo. Mas eu conheci duas que a gente conversou mais no dia da palestra, no primeiro dia. Tinha outras pessoas que tinham a doença em outros locais, homens também estavam lá. Aí eu sempre via as mesmas pessoas porque ia todo dia. Acaba fazendo amizade... é muito tempo! (Dona Deuseli)

Nessa sala de espera, essas mulheres criam uma rede de solidariedade onde compartilham experiências, sensações, dores, formas alternativas de lidar com o tratamento. Laços de amizades são estabelecidos e com eles as trocas de informações, o compartilhamento da dor, as soluções encontradas. Essas mulheres relatam que até mesmo a maneira como vivenciam a relação com a morte é conversada.

O câncer é uma doença estigmatizante, onde se trava uma "batalha" no procedimento terapêutico. Alguns procedimentos são mutiladores e transformam a condição física, emocional, social e sexual da paciente. Outros causam náuseas, vômitos, queda de cabelo, fraqueza, palidez, sangramento, diarreia, prisão de ventre, fadiga, alterações da pele e unhas. As categorias ou expressões usadas para definir tais procedimentos, como "guerra contra o câncer", revelam a dramaticidade e igualam-nos aos estigmas da doença, que "consome a pessoa" e deve ser "atacada". Assim, do diagnóstico ao tratamento, a paciente vai do ataque ao contra-ataque, adentrando em uma "guerra" onde espera sofrer efeitos desconhecidos e que supõe serem avassaladores sobre seu corpo, fazendo-a viver reestruturações radicais na sua vida. Trata-se de um agravo estigmatizado que tem um tratamento, também, estigmatizado.

Assim, na vivência desse estigma, espera-se encontrar mulheres que sofrem de uma doença grave, mortal, e os espaços onde elas se encontram também devem expressar esse sofrimento, na visão de alguns profissionais de saúde. Em geral, a sala de espera é um local onde impera o sofrimento. Por isso, as intervenções em salas de espera, que pretende produzir um ambiente acolhedor, são experiências recentes. Uma forma de intervenção é o acolhimento, o qual é uma das diretrizes da Política Nacional de Humanização (PNH), de 2003. O significado de acolher é criar uma ação de aproximação, de estar com, uma atitude de inclusão. No entanto, diante do fato de ser uma experiência recente, há muito a ser discutido para efetivá-lo, movido pela crítica dos espaços no interior dos hospitais, postos de saúde e etc. Nas salas de espera, a ordem do silêncio, do ambiente sisudo, totalmente relacionado com a proximidade com a morte são os elementos que os profissionais de saúde entendem que deve vigorar. Supõe-se que essas mulheres se encontram diante da morte a todo o momento, por isso a sala de espera não é o local para se fazer entrevistas, pois lá está sendo travada uma batalha. A presença da pesquisadora nas salas de espera foi questionada por alguns profissionais do HUB que não trabalhavam especificamente com as pacientes.

No processo de saúde-adoecimento dessas mulheres, conforme foi visto anteriormente, elas passaram pela proximidade com a morte, principalmente, quando descobriram a doença. Mas, ao longo do tratamento, na sala de espera, elas 
subvertem o silêncio e a imposição de serem contidas. Elas conversam, se conhecem, descobrem outros tipos de câncer, discutem o tratamento, enfim fazem tudo o que não é feito com o médico. Seria como se essas mulheres se subvertessem enquanto sujeitos e se elevassem acima dos estigmas que lhes são impostos pela sociedade, antes, durante e após o tratamento, e criassem suas terapêuticas. Essas redes de apoio, que são criadas ao largo do discurso e procedimentos médicos, devem ser levadas em consideração e reconhecidas, pois são fomentadas por pessoas que usufruem dos serviços de saúde, alvos de uma gestão e programação política que não as alcançam em sua plenitude, criando e reinventando dentro desses serviços alternativas de cuidado que complementam o tratamento do HUB.

\section{Considerações finais}

Com relação às tecnologias empregadas no tratamento do câncer, as mulheres enfatizam a dor e não as relacionam com a cura, mas elas situam a "salinha" como o local onde se encontra uma melhora no processo de saúde-adoecimento. Deve-se enfatizar que essa "salinha" expressa a sociabilidade como uma forma de terapêutica. Por sua vez, os profissionais de saúde enfatizam as tecnologias usadas como revolucionárias e efetivas. O desenvolvimento tecnológico é um elemento importante no tratamento do câncer e em diminuir a mortalidade, por conseguinte, não se está questionando aqui sua efetividade. O propósito deste trabalho é analisar como as pessoas entendem e vivem o uso da tecnologia. Portanto, para os profissionais de saúde, desde a sua inauguração, o Centro de Alta Complexidade em Oncologia (CACON) do HUB, se tornou uma referência na rede pública do DF, devido à importância dos equipamentos de ponta que são utilizados no combate ao câncer.

Nas falas dos profissionais de saúde entrevistados, é possível identificar a importância dada às tecnologias empregadas no tratamento. Quando questionados a respeito dessas para o tratamento do câncer no HUB, esses reconhecem somente a modernidade desses instrumentos:

$O$ aparelho de braqui, o acelerador linear da tele, e a tomografia para diagnóstico de imagem [são os aparelhos usados no tratamento].

Aqui nós utilizamos o planejamento 3D, que é com tomografia [...]. Nos outros lugares, eles utilizam o 2D. Aqui a qualidade do tratamento é muito melhor.
Planejamento tridimensional. Nos outros lugares é 2D, o médico apalpa o paciente pra tentar saber mais ou menos onde o tumor está. Aqui fazemos a tomografia, onde é possivel desenhar o tumor, saber o tamanho exato dele, quais órgãos estão prejudicados, quanto de dose será aplicado no tumor, quais as chances do paciente... é mais complexo.

É possível perceber que a ênfase dada ao tratamento de câncer de colo uterino pelos profissionais envolvidos diariamente no atendimento às pacientes portadoras desta doença é destinada exclusivamente às máquinas e equipamentos de ponta, além de metodologias de trabalho consideradas de última geração e que contemplem todos os aspectos clínicos do tumor. Consequentemente, o apoio familiar, o convívio e as conversas com a equipe de profissionais do Hospital e as crenças das mulheres não são levadas em consideração para os processos de recuperação e cura das mesmas. Principalmente, a terapêutica coletiva criada por essas mulheres no HUB é invisível aos mesmos. Tais situações não poderiam estar fomentando novas tecnologias?

Além das vivências com outras/outros pacientes na "salinha", revelando uma tecnologia de cuidado baseada na sociabilidade, as pacientes enfatizam as conversas com as enfermeiras como elemento importante ao longo do tratamento. O tratamento respeitoso de se referir a elas pelo nome e informar sobre os cuidados que devem ter sinaliza a importância da abertura para o diálogo. O contraditório nessa interação é que a enfermeira afirma que explica e informa, mas acredita que as mulheres saem sem compreender nada. Essa atitude demonstra o desconhecimento sobre o universo dessas mulheres e a ausência de um verdadeiro diálogo, pois as pacientes acabam por não serem realmente ouvidas. Por conseguinte, percebe-se que a maneira como as informações são transmitidas não inclui essas mulheres na terapêutica e no autocuidado. Esses procedimentos, ainda, seguem protocolos que são os mesmos para todas/os e não são efetivamente uma via de mão dupla. Caso fossem, poderiam levar à criação de procedimentos singulares. Mas, as indicações feitas pelos profissionais de saúde são exclusivamente para transmitir o saber biomédico, desconsiderando a opinião e o saber das pacientes. Portanto, as tecnologias acabam por demandar um autocuidado marcadamente homogeneizador de corpos. No entanto, a maneira como essas mulheres estão se apropriando do espaço do hospital, o que estão fazendo na "salinha”, revela que as mesmas acabam por assumir, a partir de suas perspectivas, o seu cuidado. 


\section{Colaboradores}

SMF Guimarães e PE Oliveira participaram igualmente de todas as etapas de elaboração do artigo.

\section{Referências}

1. Instituto Nacional de Câncer (Inca). Estimativa 2012: Incidência de Câncer no Brasil. Rio de Janeiro: Inca; 2011.

2. Pinotti JA, Piato JRM, Ricci MD, Piato S. Oncologia ginecológica: aspectos atuais do diagnóstico e do tratamento. São Paulo: Manole; 2008.

3. Anjos ACY. A experiência da terapêutica quimioterápica oncológica na visão do paciente. Rev Latino-Americana de Enfermagem 2006; 14(1):33-40.

4. Helman CG. Cultura, saúde e doença. $4^{\text {a }}$ ed. Porto Alegre: Artes Médicas; 2003.

5. Maruyama SAT. A experiência da colostomia por câncer como ruptura biográfica na visão dos portadores [tese]. Ribeirão Preto: USP; 2004.

6. Cardoso de Oliveira R. O trabalho antropológico: olhar, ouvir e escrever. Rev Antropologia 1996; 39(1):13-37.

7. Minayo C, Gomes S, organizadores. Pesquisa social: teoria, método e criatividade. Rio de Janeiro: Ed. Vozes; 2012.

8. Ribeiro Corossacz V. Dois mundos confrontados: as histórias reprodutivas dos médicos e as pacientes. In: Ribeiro Corossacz V. O corpo da nação: classificação racial e gestão social da reprodução em hospitais da rede pública do Rio de Janeiro. Rio de Janeiro: Ed. UFRJ; 2009. Capítulo 7.

9. Langdon J. 1995. A Doença como Experiência: A Construção da Doença e seu Desafio para a Prática Médica. São Paulo: Escola Paulista de Medicina; 1995. Palestra oferecida na Conferencia 30 Anos Xingu. [mimeo]

10. Gerhardt T. Itinerários terapêuticos em situações de pobreza: diversidade e pluralidade. Cad Saude Publica 2006; 22(11):2449-2463.

Artigo apresentado em 26/09/2014

Aprovado em 24/11/2014

Versão final apresentada em 26/11/2014 